\title{
A continuous velocity field for Norway
}

\author{
Halfdan Pascal Kierulf • Mohammed Ouassou • \\ Matthew James Ross Simpson • Olav Vestøl
}

Received: 3 March 2012 / Accepted: 18 October 2012 / Published online: 9 November 2012

(C) The Author(s) 2012. This article is published with open access at Springerlink.com

\begin{abstract}
In Norway, as in the rest of Fennoscandia, the process of Glacial Isostatic Adjustment causes ongoing crustal deformation. The vertical and horizontal movements of the Earth can be measured to a high degree of precision using GNSS. The Norwegian GNSS network has gradually been established since the early 1990s and today contains approximately 140 stations. The stations are established both for navigation purposes and for studies of geophysical processes. Only a few of these stations have been analyzed previously. We present new velocity estimates for the Norwegian GNSS network using the processing package GAMIT. We examine the relation between time-series length and precision. With approximately 3.5 years of data, we are able to reproduce the secular vertical rate with a precision of $0.5 \mathrm{~mm} /$ year. To establish a continuous crustal velocity field in areas where we have no GNSS receivers or the observation period is too short to obtain reliable results, either interpolation or modeling is required. We experiment with both approaches in this analysis by using (i) a statistical interpolation method called Kriging and (ii) a GIA forward model. In addition, we examine how our vertical velocity field solution is affected by the inclusion of data from repeated leveling. Results from our geophysical model give better estimates on the edge of the network, but inside the network the statistical interpolation method performs better. In general, we find that if we have less than 3.5 years of data for a GNSS station, the
\end{abstract}

H. P. Kierulf $(\varangle) \cdot$ M. Ouassou · M. J. R. Simpson · O. Vestøl Geodetic Institute, Norwegian Mapping Authority,

3511 Hønefoss, Norway

e-mail: halfdan.kierulf@kartverket.no

H. P. Kierulf

Department of Geosciences, University of Oslo,

0316Oslo, Norway interpolated value is better than the velocity estimate based on a single time-series.

Keywords Velocity field · GNSS · Kriging · GIA

\section{Introduction}

The establishment of a permanent Global navigation satellite system (GNSS) network in Norway began in the early 1990s. By the end of 2000, the network contained 15 continuously operating GNSS receivers, with around a third of these contributing data to the International GNSS Service (IGS) and/or the European Permanent Network (EPN). Following 2003, the network has undergone a densification (largely for navigation purposes) and now contains approximately 140 stations on the Norway mainland with an average spacing of $60 \mathrm{~km}$ (Fig. 1). This network provides a means to establish a well-constrained velocity field for Norway and a powerful tool for the study of geophysical phenomena. In this study, we examine data from the Norway mainland GNSS network as of the start of 2011. For stations where we have sufficiently long time-series, the majority of which have not been analyzed before, we present new GNSS derived velocities.

Observations of Glacial Isostatic Adjustment (GIA) from across Fennoscandia (the geographic areas of Finland, Norway and Sweden) show the ongoing relaxation of the Earth in response to past ice mass loss (e.g., Fjeldskaar 1994; Lambeck et al. 1998a,b; Milne et al. 2001; Johansson et al. 2002; Kierulf et al. 2003; Lidberg et al. 2007, 2010). Data from permanent GNSS stations provide a measure of movements in both the vertical and horizontal components of motion (Nocquet et al. 2005). The GNSS observations show two main features. Firstly, a pattern of Earth uplift with highest rates ( $\sim 10 \mathrm{~mm} /$ year in Gulf of Bothnia) corresponding to 


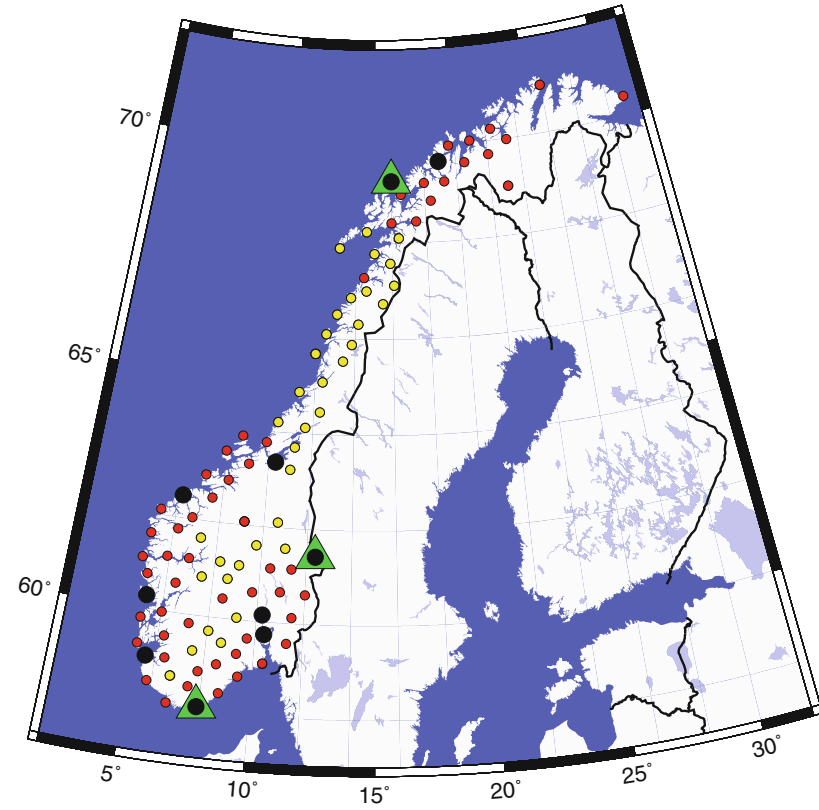

Fig. 1 Permanent GNSS stations on the Norway mainland. The black circles mark high quality sites established in 2000 or earlier for geodetic purposes (these stations are ANDO, ALES, BRGS HFSS, KRSS, OSLS, STAS, TROM, TRO1 and TRYS). Red and yellow circles mark stations established after 2001 and mainly built to serve the Norwegian positioning service. The yellow circles mark stations established after 2008 and are not used for the velocity estimates. Green triangles mark stations that are discussed in Sect. 4

areas of thickest ice during the last glacial period $(\sim 21,000$ years ago). Rates with lower, but still positive values, are shown for most of Norway (e.g., Vestøl 2006). Secondly, horizontal movements indicate a regional deformation characterized by an outward spreading from the centre of past maximum ice thickness.

Much of the previous work has been completed under the landmark Baseline Inferences for Fennoscandian Rebound, Sea-level, and Tectonics (BIFROST) project. Results from the BIFROST network have been published regularly (e.g., Milne et al. 2001; Johansson et al. 2002; Lidberg et al. 2007, 2010) and include some Norwegian and North European stations. In a separate investigation, Vestøl (2006) presented a model of land uplift based on a collocation method. He used observations from leveling, tide gauges and GNSS data from Fennoscandia and the nearby areas of continental Europe [the GNSS velocities used in his analysis are the same as in Lidberg et al. (2007)].

In this study, we use a scientific GNSS analysis software to derive daily results for the permanent Global Navigation Satellite System (GNSS) stations on the Norway mainland (Sect. 2). In the early years the Norwegian GNSS network went through several upgrades and equipment changes. After May 2000 the situation has been more stable. We have, therefore, opted to only include data from 2000-05-01 and later.
We have tested the precision of the time-series related to the total observation time (Sect. 3).To derive velocities in areas without GNSS or where the GNSS stations have observation periods that are to short to make reliable velocity estimates, we have developed two different interpolation routines based on the statistical concept of Kriging (Cressie 1993). We will also interpolate our results using geophysical model of Glacial Isostatic Adjustment (GIA) and leveling (Sect. 4).

GNSS results from the Arctic Norwegian islands Svalbard, Hopen, Bjørn Øya and Jan Mayen are not included in this paper. Results from Svalbard can be found in Kierulf et al. (2009a,b).

\section{GNSS analysis-strategies}

We use the GNSS analysis software GPS Analysis Software of MIT (GAMIT) (Herring et al. 2011). This software makes use of the so-called Double Difference (DD) approach, where a network of GNSS stations is analyzed in a single adjustment. A least square adjustment is used for parameter estimation. This implies that parameters which vary with time, for example, the troposphere, have to be estimated as piecewise linear parameters. The atmospheric zenith delay was estimated with a 2 hourly piecewise linear model together with a daily troposphere gradient. Ocean-loading coefficients (Scherneck 1991) from the FES2004-model are used. To model the tropospheric delay Vienna Mapping Functions (VMF) (Boehm et al. 2006) was used. The (igs05_*.atx) was used to model the phase centre variations. We have used a cut-off elevation of $7^{\circ}$.

To reduce the computational time, our network was divided into sub-networks analyzed individually and later on combined to daily results using GLOBK (Herring et al. 2011) to daily results. The daily result files were then transformed into ITRF2008 in a two step procedure. In the first step, a network of northern European IGS stations from the areas around Norway (GRAS, HERT, KIR0, MAR6, MDVO, METS, MORP, NYA1, NYAL, ONSA, POTS, RIGA, TRO1, TROM, WSRT and WTZR) were used to transform the minimally constrained daily solutions into ITRF2008. Preliminary results for all stations were extracted and velocities were computed. In the second step the procedure was repeated using the output from the first step, but this time including the vast majority of the Norwegian stations. This two step procedure using the dense-network stabilization will be more robust since we have a stronger realization of the frame on each day. This approach will remove most of the so-called common mode error, but since our connection to the ITRF is through a regional set of IGS stations, our results are partly de-coupled from the global reference frame. See Legrand et al. (2010) for a detailed analysis of the limitations 
of regional reference frame realizations. Appendix 7.1 also includes a more general discussion on reference frame realizations and comparisons to previous studies.

\section{Examination of time-series}

It is widely recognized that the assumption of only white noise content is unrealistic for GNSS time-series (Johnson and Agnew 1995; Zhang et al. 1997; Mao et al. 1999; Williams et al. 2004). Williams et al. (2004) recommend a noise model combining both white noise and flicker noise for most GNSS sites. In this study the time-series analysis were performed using the CATS software (Williams 2008), using both a white noise model and a combination of white noise and flicker noise. We opt to include annual and semi-annual signals as additional parameters in our timeseries analysis. In addition, parameters for offsets for all antenna and radome changes where included in the timeseries analysis as well as parameters for offsets where breaks in the time-series were obvious after a visual inspection.

To examine the stability of velocity estimates we have performed a convergence analysis using solutions from stations established in year 2000 or earlier (black circles in Fig. 1). Velocities have been computed for each time-series, first using only the last 2.5 years of data, then the last 3.0 years of data and then extending the time period by 0.5 years until the last 10 years of data have been included. The RMS of the differences between the velocities for the shorter period and the velocities for the complete time-series (back to 200005-01, prior to this date equipment changes were performed more frequently and, therefore, results were less reliable) are calculated for each time span and component (Eq. 1).

$R M S(\Delta t)=\sqrt{\sum_{i=1}^{n} \frac{\left(r_{i}(\Delta t)-\overline{r_{i}}\right)^{2}}{n}}$,

where $r_{i}(\Delta t)$ is the rate for station $i$ with time-series of length $\Delta t . \overline{r_{i}}$ is the rate for station $i$ using the complete time-series back to 2000-05-01 and $n$ is the number of stations. This test gives a measure of the stability of the estimated secular rates as function of time-series length. Convergence studies for single stations time-series have earlier been performed for instance in Scherneck et al. (2002) and Vespe et al. (2002). The RMS differences are plotted in Fig. 2. We find that a precision of $0.5 \mathrm{~mm} /$ year is achieved after 3.0 , 2.5 and 3.5 years in the north, east and vertical components, respectively. A $0.2 \mathrm{~mm} /$ year precision is achieved after 4.0 , 5.5 and 5.5 years in the north, east and vertical component, respectively.

In Fig. 3, the mean uncertainties of the velocity estimates are plotted against time-series length. The uncertainty estimations are based on a noise model that includes white and flicker noise (Williams 2008). Stations with 3.5 years of

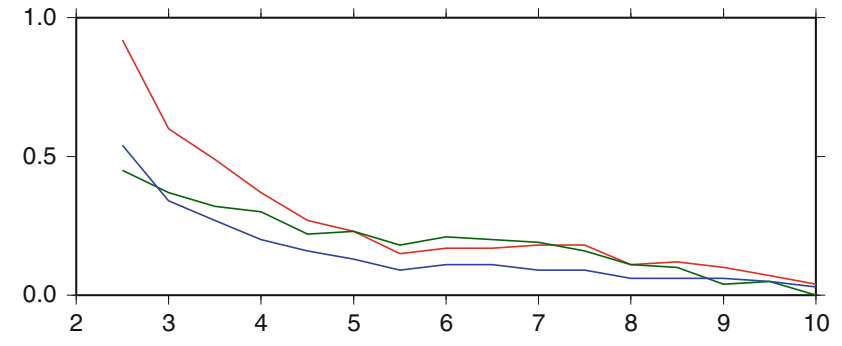

Fig. 2 Stability of the velocity estimates. RMS differences between velocity estimates for a time-series of a given length and the velocity for the complete time-series. The north component is blue, east is green and height is red. The $y$ axis is in mm/year and the $x$ axis is length of the time-series given as the start time of the time-series in year before 2011

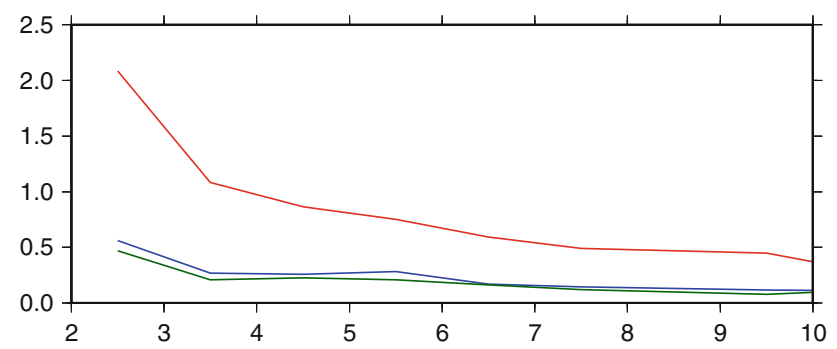

Fig. 3 Uncertainties of the velocity estimates. Mean uncertainties of the velocity estimates are plotted against time-series length. North component is blue, east green and height red. The $y$ axis is in $\mathrm{mm} / \mathrm{year}$ and the $x$ axis is length of the time-series given as the start time of the time-series in year before 2011

data have a mean uncertainty of $1.0 \mathrm{~mm} / \mathrm{year}$ in the vertical and $0.3 \mathrm{~mm} /$ year in the horizontal components. To achieve a mean uncertainty of $0.5 \mathrm{~mm} /$ year, 3.0, 2.5 and 7.5 years of data are needed for the north, east and vertical components, respectively.

\subsection{Discussion on time-series analysis and time-series length}

The accuracy and precision of velocity estimates from geodetic time-series strongly depend on the length of the timeseries. According to Blewitt and Lavallée (2002) 2.5 years of data is sufficient to get precise velocity estimates if you account for periodic variations. If you only include secular rate and offset in the regression model then 4.5 years of data are required. Note that Blewitt and Lavallée (2002) implicitly assumed only white noise in the time-series. Bos et al. (2010) performed a similar analysis including power-law and white noise. They showed that the effect of including or not including an annual signal in the time-series analysis, is much larger when a power-law plus white noise model is used instead of a pure white noise model. Teferle et al. (2009) argue that annual and semi-annual signals can bias the velocity 

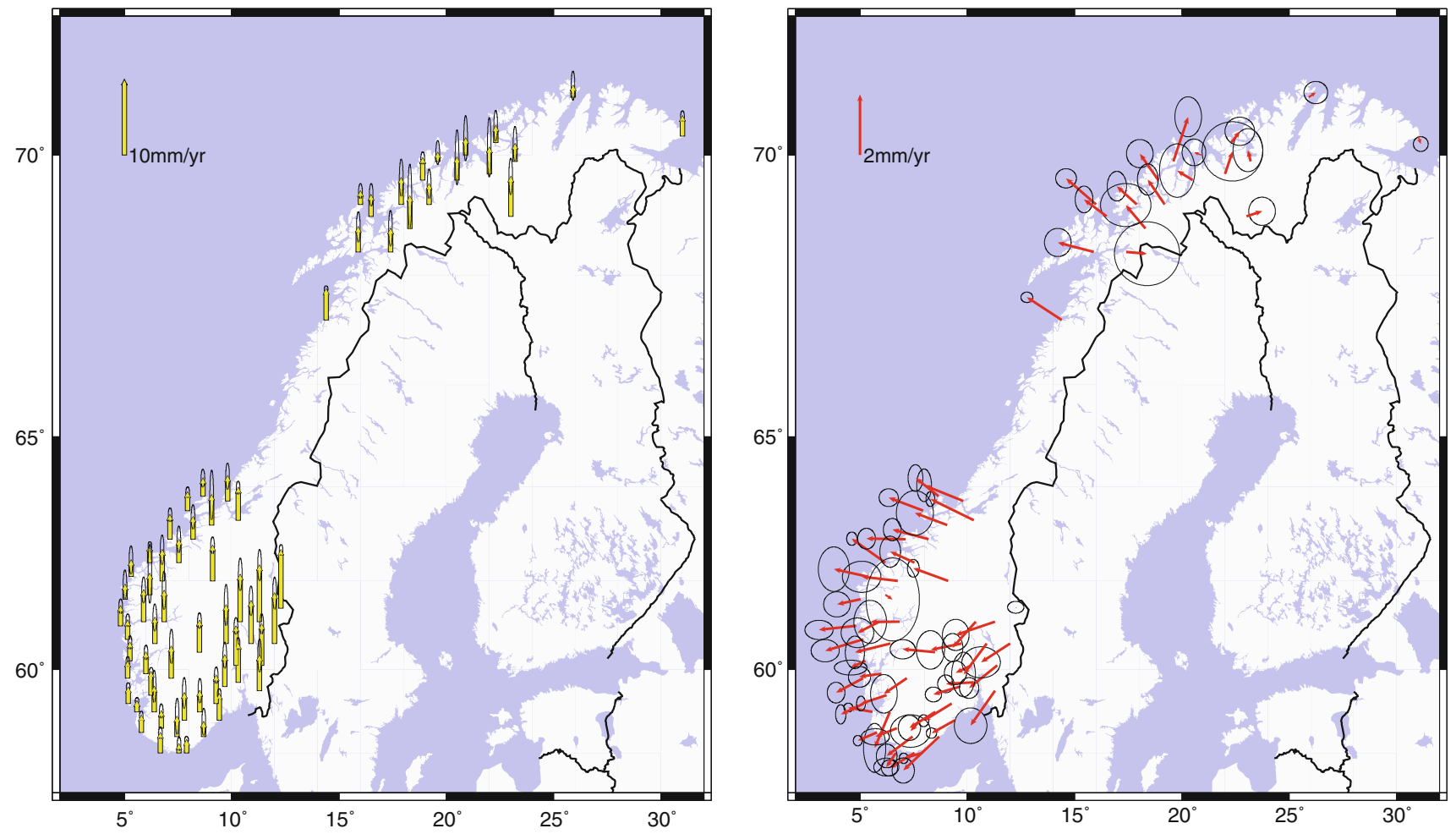

Fig. 4 Land uplift (left) and horizontal velocities (right) in Norway. The land uplift is in ITRF2008. The horizontal velocities are relative to the stable Eurasian plate (Boucher and Altamimi 2011). The probability ellipses $(2 \sigma)$ are based on a noise model including white and flicker noise

estimates also for time-series exceeding 4.5 years if the signal are large.

In King et al. (2010) theoretical vertical site velocity uncertainties for stations in the Northern Hemisphere of $1.41,1.58$ and $0.54 \mathrm{~mm} /$ year after 5 years of observations and $0.71,0.79,0.27 \mathrm{~mm} /$ year after 10 years of observations are derived using DD, Precise Point Positioning (PPP) and regional stacking, respectively. The uncertainties in the horizontal components are between a third and a fourth in the Double Difference (DD) solution and between half and a third in the Precise Point Positioning (PPP) solution. These theoretical uncertainties agree with the empirical values derived in the time-series analysis and summarized in Fig. 3. See also Santamaria-Gomez et al. (2011) for a study of the time evolution in the noise characteristics of the time-series.

We have opted to include stations with more than three years of data only, and find them sufficient for the precision needed in the analysis described further in this paper. However, we recognize that increasing the time span to five years of data improves the precision considerably, especially in the vertical component.

The velocities off all stations with at least three years of data are plotted in Fig. 4. The horizontal velocities are given relative to the stable Eurasian plate as described in Boucher and Altamimi (2011).
The tests conducted here provide information on the precision and stability of the velocity estimates, but not their absolute accuracies. That is, systematical errors in the reference frame realization, errors in the GNSS analysis strategy or local secular motion of the antenna monument may also affect our velocity solutions (see e.g. King et al. 2010; Wu et al. 2011) and Appendix 7.1 for a more detailed discussion).

\section{Establishing a continuous velocity field for Norway}

To establish a continuous crustal velocity field in areas where we have (1) no GNSS receivers or (2) the observation period is too short to obtain reliable results, either interpolation or modeling is required. In the first part of this Section we show results from a statistical interpolation method called Kriging. In the second part we present results from a GIA forward model constrained by the GNSS data. In Sect. 4.3 repeated leveling is used as as an additional constraint on the vertical velocities.

The different methods are tested in Sect. 4.4. The observed velocities used here are based on the GNSS time-series of three years or longer, which leaves us with a total of 66 stations. 

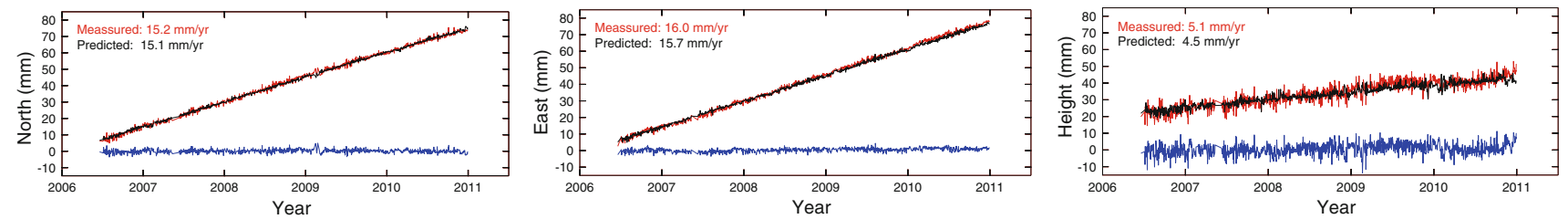

Fig. 5 Observed and predicted time-series for HFSS (Hønefoss). Red is observed, black is predicted and blue is the difference. The estimated rates for the measurements (resp. predictions) are given in red (resp. black)

\subsection{Statistical interpolation}

We have used the linear spatial interpolation algorithm, ordinary Kriging (Cressie 1993). The necessary theory and formulas for Kriging are described in Cressie (1993). One of the critical conditions for a successful global interpolation routines are accurate knowledge about the covariance structure. One tool, often used in Kriging, is the variogram or semivariogram. Semivariogram is defined in Cressie (1993).

We will use the interpolation routines in two different ways. First using the daily coordinates for stations in the network to predict daily coordinates for the new point and then using these daily values to estimate the velocities. Second, we will use the velocities already established (Sect. 3) to predict velocities in new points.

\subsubsection{Predicting time-series}

Daily 3D coordinates from the complete Norwegian GNSS network are used to predict new daily coordinates for a location inside the network, where we have no observations. To find the covariance structure we have used the semi-variogram. Time-series for the predicted location are extracted from these daily predictions. The RMS of the differences between the daily predictions and observations vary from 0.8 to $1.2,0.8$ to $1.4,2.6$ to $3.3 \mathrm{~mm}$ in the north, east and vertical component respectively. For HFSS, the corresponding numbers are $0.9,0.9$ and $3.0 \mathrm{~mm}$. Figure 5 shows the predicted time-series for the location Hønefoss (HFSS) in southern Norway as well as the observed time-series for the same location (Note: results from HFSS was excluded before performing the daily predictions). We see a very good agreement between observations and predictions both for the long-term evaluation of the coordinates, but also for shortterm fluctuations. This indicates that the method provides a good reconstruction of real observations and hence might be used both for predictions in areas where we have no observations or to extend short time-series into periods without observations. Statistical predictions based on this method are hereafter called SP-TS.

\subsubsection{Predicting velocity field}

As shown in Fig. 4, there is clearly a case of missing observations: no velocity observations are available for latitudes between $65^{\circ}$ and $68^{\circ}$, as well as the locations north-east of Norway.

The missing value problem is handled by a set of advanced procedures with a common purpose: producing plausible values for the missing observations. One of the stronger approaches is the Bayesian one, which simply treats the missing data as extra parameters (Sorensen and Gianola 2002).

Our aim is to construct a continuous velocity field for the entire country by using the available observations. The imputation procedure used to accomplish this goal is an iterative and linear spatial interpolation algorithm, also known as local Kriging. This algorithm is capable of completing the data set by replacing missing observations with predictions. For an example where Kriging have been applied in a similar application see e.g. Teza et al. (2012) where a strain rate map was developed for Northern Victoria Land.

At first, the empirical covariance function is estimated using data solely from southern Norway. The result is then used to generate predictions for some locations above $65^{\circ}$ latitude. These are in turn used, alongside the original data-set, to re-compute the empirical covariance function and subsequently make more predictions in the border region. The observation area is expanded, and the process is repeated until the velocity field covers the entire Norwegian mainland, and the missing observations have been reconstructed. The velocity field is shown in Fig. 6, and the accompanying variability is visualized by the variogram in Fig. 7 .

The estimation process involves alternating between (1) a step that computes the empirical covariance function using local Kriging, and (2) a step that merges the predictions with the original data, as a complete observation. Hereafter we call this statistical interpolation method for SP-VF.

\subsection{Modeling velocities}

The GIA model employed is composed of three components: a model of grounded past ice evolution (for Fennoscandia and other ice-covered areas), a sea level model to compute the redistribution of ocean mass for a given ice and Earth model, 

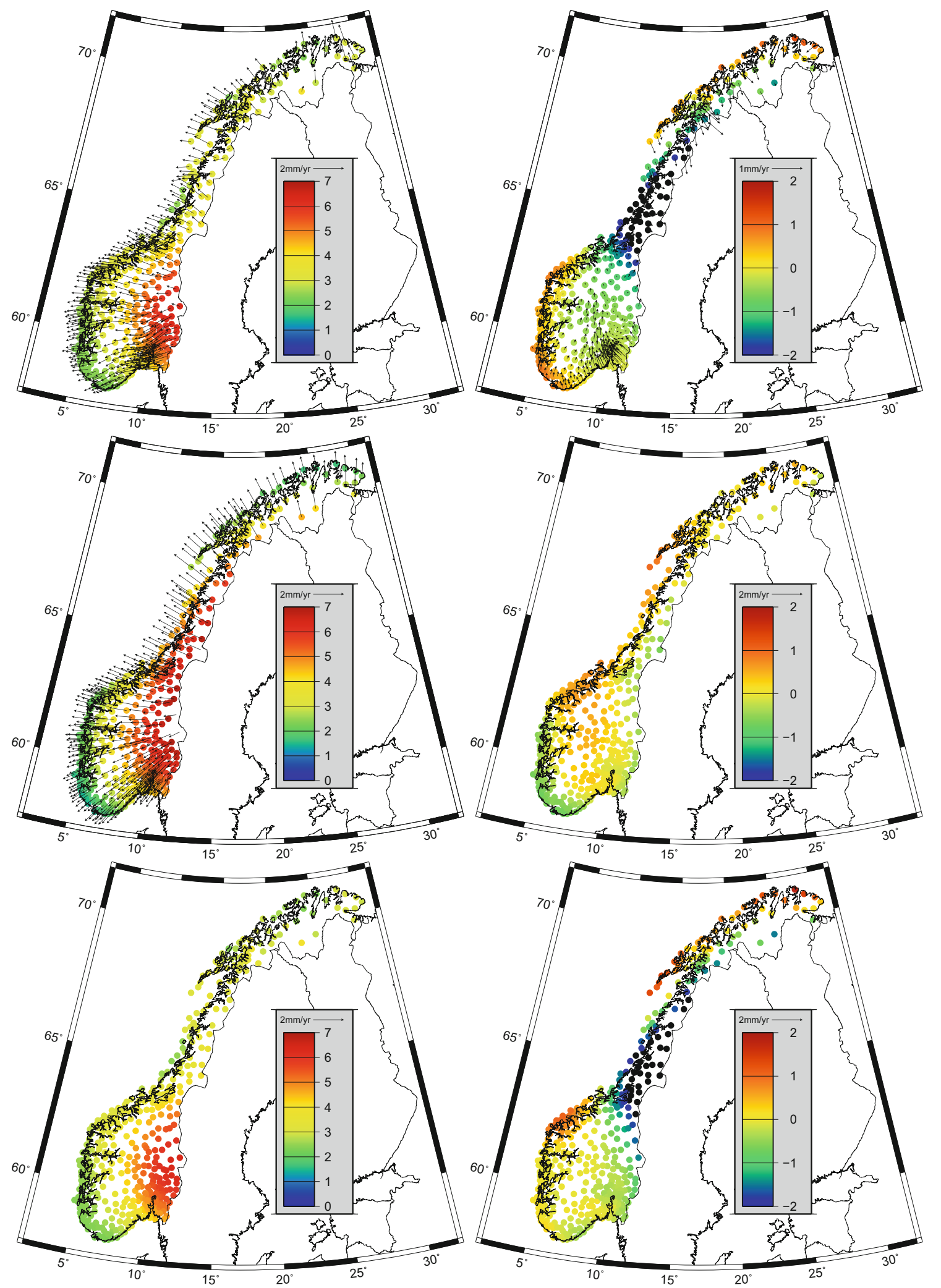

Fig. 6 Velocity fields for Norway. Vertical velocities are given in ITRF2008 while horizontal velocities are transformed to the stable Eurasian plates (ETRF2000). The left panels are from top to bottom; the statistical prediction (SP-VF), the GIA model (GIA-3D) and Leveling

(LP). The right panels are from top to bottom the differences between; statistical prediction and the GIA model, the GIA model and leveling, and statistical prediction and leveling 

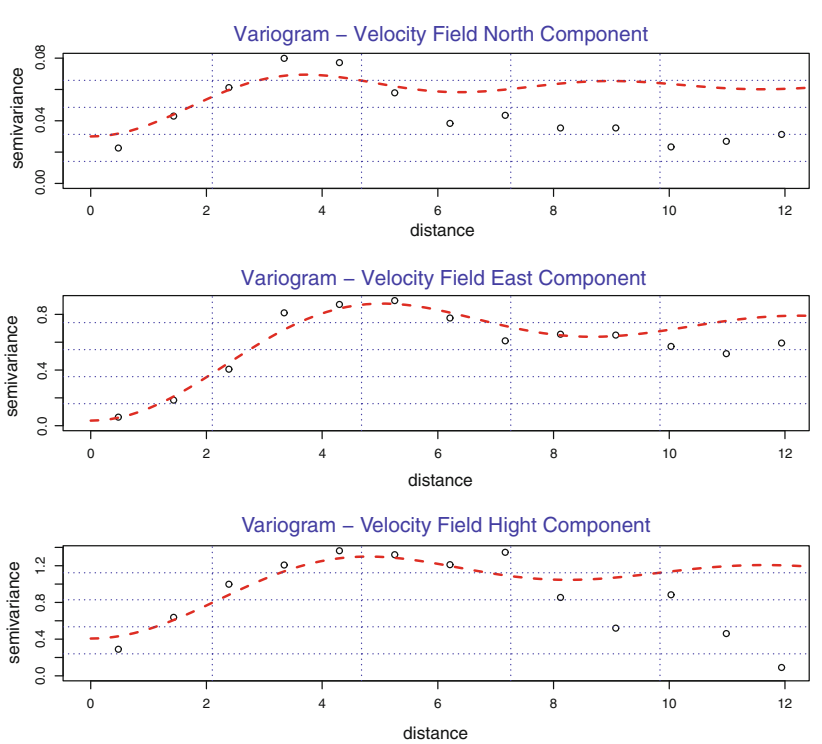

Fig. 7 Variogram for the three components of the velocity field. Black circles indicate the empirical semivariogram, while the dashed red lines indicate the theoretical models fitted by restricted maximum likelihood. The horizontal axis represents the lag distance in degrees, while the vertical one represents the variability of the velocity field

and an Earth model to compute the solid Earth deformation associated with the ice-ocean loading history. The GIA model used here, and the method used to calculate present-day land motion, is the same as applied by Milne et al. (2001) except that the sea level component of the model was improved as discussed in Mitrovica and Milne (2003) and Kendall et al. (2005).

Past GIA modeling studies have used both paleo sea level data (e.g. Lambeck et al. 1998b) and/or GNSS observations (e.g. Milne et al. 2001, 2004) to help constrain Earth model parameters. These investigations have shown that it is not yet possible to uniquely constrain the Earth viscosity structure for the Fennoscandia region but provide us with a range of Earth parameter values that satisfy the various GIA observables. The main aim of the GIA modeling work performed here, however, is to test how well the model performs in areas where we have no observations (in comparison to the statistical interpolation method), rather than as an investigation of the Earth viscosity structure. This assumes that, after correcting for horizontal plate motion, crustal deformation is solely attributable to the GIA signal.

To perform the test, we constrain the model using a subset of 56 of the total 66 GNSS observations available (the stations marked as red circles in Fig. 1). The 10 GNSS locations not used as a constraint (black circles in Fig. 1) are control stations. We use these to see how well the model reproduces the observed velocities (see following Section).

Given our limited knowledge of the Earth viscosity structure for Norway, we generate predictions of present-day vertical land motion using a suite of 297 Earth viscosity models.

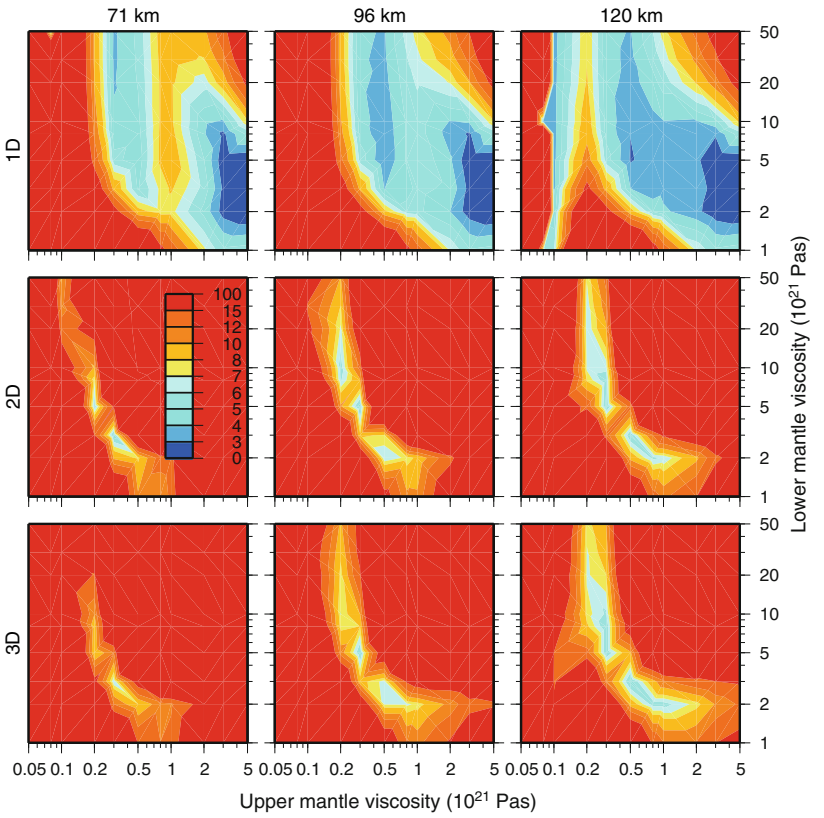

Fig. 8 Goodness of fit for GIA-model, using the reduced $\chi^{2}$ criterion. The key gives the $\chi^{2}$ values (see Eq. 2). Top panels show results for the vertical component (1D), middle panels for the horizontal components (2D) and bottom panels for all 3 components (3D). As noted previously, we correct for horizontal plate motions following Boucher and Altamimi (2011)

The range of values we explore is similar to those as in Milne et al. (2001, 2004), namely; lithospheric thickness is varied from 71 to $120 \mathrm{~km}$, upper mantle viscosity from $0.05 \times 10^{21}$ to $5 \times 10^{21}$ Pas and lower mantle viscosity from $10^{21}$ to $50 \times 10^{21} 21$ Pas. To determine an optimal Earth model (i.e. the model which gives best-fit to the GNSS data) we conduct a simple statistical test. We compute vertical and horizontal velocities at the 56 GNSS stations considered for each of the 297 Earth models introduced above and quantify the goodness of fit for each Earth model using the reduced $\chi^{2}$ criterion:

$\chi^{2}=\frac{1}{n} \sum_{i=1}^{n}\left(\frac{y_{i}^{\mathrm{pred}}-y_{i}^{\mathrm{obs}}}{\sigma_{i}}\right)^{2}$.

The $\chi^{2}$ value indicates the difference between the predictions from the GIA-model $y_{i}^{\text {pred }}$ and the observed vertical velocity $y_{i}^{\text {obs }}$ for a specified observational error $\sigma_{i}$ and given GNSS station $i$ ( $\sigma_{i}$ is the uncertainty of the velocity estimates found assuming a combination of white noise and flicker noise). A value of 1 or less indicates a good fit to the data.

Figure 8 shows how goodness of fit to the GNSS observations varies with Earth model parameters. We find broadly similar results to Milne et al. (2001, 2004), namely, that the vertical velocities favor an Earth model with a relatively stiff upper mantle whereas horizontal rates suggest a weaker one. Differences between $\chi^{2}$ values for the various lithospheric thicknesses are small. Results from a more comprehensive 
investigation, however, suggest a preference for a lithosphere of $100 \mathrm{~km}$ or thicker for Fennoscandia (Milne et al. 2004). For the models with a $120 \mathrm{~km}$ lithospheric thickness, an upper mantle viscosity of $5 \times 10^{21}$ Pas and lower mantle viscosity of $3 \times 10^{21}$ Pas gives best-fit to the GNSS data in the vertical component (hereafter called GIA-1D model). We note that other studies have inferred Earth viscosity values differing to ours and indicate significant lateral variations of Earth structure across Fennoscandia (Steffen and Wu 2011).

In comparison to the vertical component, the GIA model generally shows a poorer fit to the observed horizontal velocities. One reason for this is that the observational errors on the horizontal components are smaller (typically between 0.1 and $0.2 \mathrm{~mm} /$ year) which leads to higher $\chi^{2}$ values. In addition, as the horizontal motions are dominated by a rigid rotation largely driven by plate tectonic processes, isolating the GIA signal is difficult. We correct for the rigid rotation following Boucher and Altamimi (2011). Note that relatively small errors in this correction will affect the determination of the GIA signal and, in turn, the $\chi^{2}$ values. If we consider the vertical and both horizontal components, the best $\chi^{2}$-fit is for a model with a $120 \mathrm{~km}$ thick lithosphere has an upper mantle viscosity of $5 \times 10^{20}$ Pas and lower mantle viscosity of $3 \times 10^{21}$ Pas (hereafter called GIA-3D model).

Isolating the different geophysical signals is unfortunately not a straightforward problem. As mentioned, the rigid rotation we apply here is from Boucher and Altamimi (2011), which has been determined from European GNSS stations. We are aware, however, that this rigid rotation may also contain (or be contaminated by) signals attributable to GIA and already taken into account in our GIA model. Past modeling studies have shown that ongoing GIA in North America (see Mitrovica et al. 1994) and rotational effects associated with GIA (see e.g. Milne et al. 2004) produce a relatively uniform and not insignificant signal of solid Earth motion over Europe.

As it is difficult to distinguish these uniform GIA signals from the horizontal motion dominated by plate tectonics, we conduct a sensitivity test to see how a $1 \mathrm{~mm} /$ year error in the plate velocity affects our $\chi^{2}$ values and RMS of our velocity predictions. The results are plotted in Fig. 9. The grey curve shows the increase in $\chi^{2}$ relative to the GIA-3D model. We see very little increase in the $\chi^{2}$ for the best fit model when we add $1 \mathrm{~mm} /$ year to the south component of the plate velocity, but a large increase if we add $1 \mathrm{~mm} /$ year to the north and east velocities. The red (blue and green resp.) curve is the increase in RMS for the height (north and east resp.) component for a $1 \mathrm{~mm} /$ year change in the plate correction in different directions. The RMS values show similar results to the $\chi^{2}$ values.

Small errors in the plate motion model will influence our $\chi^{2}$ values and velocity predictions for the control points.

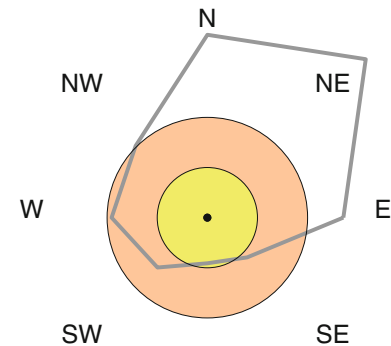

S
N

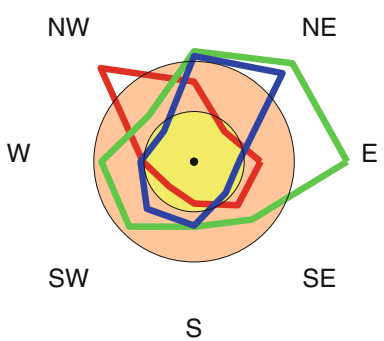

Fig. 9 Sensitivity test.Sensitivity of velocity predictions and $\chi^{2}$ values when adding $1 \mathrm{~mm} /$ year to the plate correction in E, NE, N, NW, W, SW, $\mathrm{S}, \mathrm{SE}$ and SE. The results are normalized with respect to the GIA-3D model, which is shown as the yellow circle. The orange circle marks the doubled normalized value of the GIA-3D model. The left panel shows the $\chi^{2}$ values. The right panel shows the RMS of the velocity predictions for the control points. The vertical component is shown in red, north component in blue and east component in green. Results inside the yellow area show an improvement of the $\chi^{2}$ values or RMS, while results outside the orange area show a doubling of the values

However, results from the sensitivity test (Fig. 9) demonstrate that, as long as the $\chi^{2}$ stay low also the velocity predictions stay good. The GIA predicted velocities after adding $1 \mathrm{~mm} / \mathrm{year}$ to the south component of the plate velocity are still good, while $1 \mathrm{~mm} / \mathrm{year}$ to the north degenerate the GIA model (large $\chi^{2}$ ) and make our predictions on the control points much worse.

Our technique for isolating the GIA signal is only one of several methods that can be used. For example, Kierulf et al. (2003) subtracted the GIA signal from the GNSS observations before estimating plate motion. Lidberg et al. (2007) solved for an additional rigid rotation before comparing GNSS results with GIA models. Whereas, in Hill et al. (2010) transformation parameters were included in the observation equation between observations and GIA models to account for possible reference frame problems.

To which extent another approach for isolating the rigid plate rotation and GIA would improve our velocity predictions, are not examined. However, the sensitivity test indicate that it will not improve our ability to predict velocities significantly.

\subsection{Repeated leveling as an additional constraint on the vertical velocities}

As stated in Sect. 4.1.2, there is clearly a case of missing observations in the mid- and north-eastern part of Norway. Vestøl (2006) shows that repeated leveling lines can be combined with GNSS observations in a common computation of the vertical velocity field. The leveling lines are plotted in Fig. 10.

Following the same procedure as in Vest $\varnothing 1$ (2006), repeating leveling lines have filled up the open gaps between the 


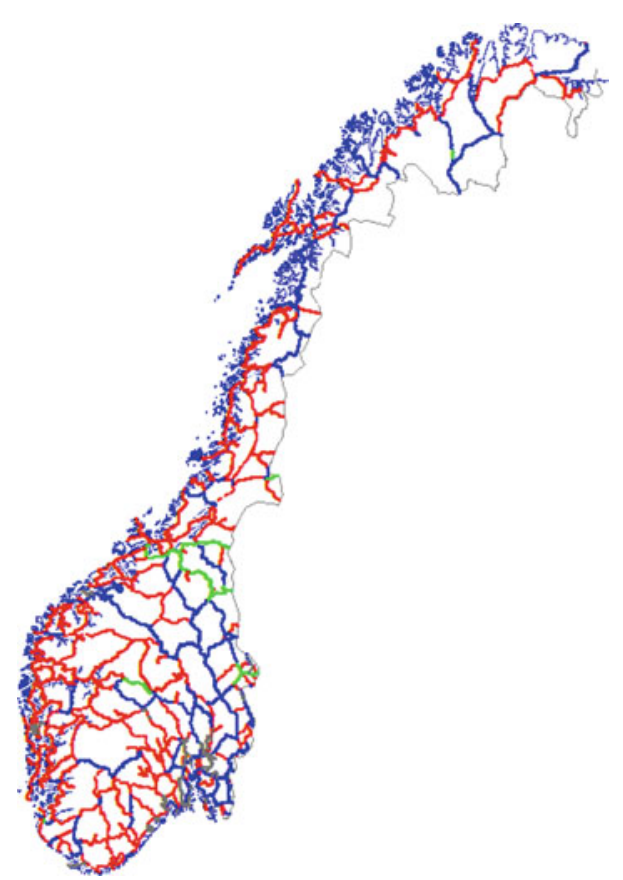

Fig. 10 Repeated leveling lines in Norway. The first order leveling network consists of lines from 1916 to 2011. The green lines are measured three times, the blue two and the red lines are measured once only. However, also the red lines from different years contain land uplift information when forming a loop. Lines from Sweden and Finland are also used in the computation, but are not shown here

Global Navigation Satellite System (GNSS) stations (the 56 stations marked as red circles in Fig. 1) and brought higher redundancy into the system. The predictions based on this method are hereafter called LP.

\subsection{Evaluation of predicted and modeled velocities}

To evaluate the precision of the statistical predictions we have compared our predictions with observed velocities for a subset of the stations (the 10 stations marked with black circles in Fig. 1). The statistical predictions were performed using the remaining 56 stations as data base. RMS values of the differences between observations and predictions are included in Table 1. The two statistical methods give almost identical results; SP-TS method is slightly better in the north component, while the SP-VF method is preferable in the east and vertical components. The vertical results are hampered by a few outliers. All the outliers are at the perimeter of the network (stations that geometrically can not be surrounded by any triangle of nearby stations). The stations are Trysil (TRYS) in the east, Andøya (ANDO) in north-west and Kristiansand (KRSS) in south (green triangles in Fig. 1). All three stations have a residual (difference between observed and predicted values) of above $1 \mathrm{~mm} / \mathrm{year}$ in the height component for at least one of the methods used. The RMS after removing these stations is included in the parentheses in
Table 1 Uncertainties of predictions

\begin{tabular}{llllll}
\hline & $\begin{array}{l}\text { OBS.- } \\
\text { SP-TS } \\
(\mathrm{mm} / \text { year })\end{array}$ & $\begin{array}{l}\text { OBS.- } \\
\text { SP-VF } \\
(\mathrm{mm} / \text { year })\end{array}$ & $\begin{array}{l}\text { OBS.- } \\
\text { GIA-1D } \\
(\mathrm{mm} / \text { year })\end{array}$ & $\begin{array}{l}\text { OBS.- } \\
\text { GIA-3D } \\
(\mathrm{mm} / \mathrm{year})\end{array}$ & $\begin{array}{l}\text { OBS.- } \\
\text { LP } \\
(\mathrm{mm} / \text { year })\end{array}$ \\
\hline North & $0.25(0.24)$ & $0.34(0.32)$ & - & $0.29(0.29)$ & - \\
East & $0.44(0.30)$ & $0.20(0.18)$ & - & $0.20(0.21)$ & - \\
Height & $0.78(0.53)$ & $0.62(0.27)$ & $0.55(0.54)$ & $0.86(0.97)$ & $0.72(0.70)$
\end{tabular}

The values are the RMS between observations and predictions for all sites established in 2000 or earlier (black circles in Fig. 1). For the values in parentheses the outliers at the perimeter of the network (green triangles in Fig. 1) are removed

Table 1. We note large improvements for both methods, but the SP-VF method gives better agreement in the height component. Not surprisingly, we can conclude that such interpolation methods are more uncertain at the perimeter of the network.

It is also two other factors worth to remember. To perform these comparisons the stations with longest time-series are used as control sites. This implies that the stations with the presumable highest precision are not included in the base of the prediction. Furthermore are almost all the oldest stations in Norway located at the coast and therefore at the edge of the GNSS network, making the prediction of these particular sites more uncertain. The RMS values given in Table 1 may therefore be regarded as upper bound for what could be expected for such types of interpolation. Using also the control stations as base for the interpolation would have improved the results from the statistical predictions. Predicted velocities in center of the network would presumable have better precision.

This comparison indicates that Kriging based on already established velocities (SP-VF) is slightly better than Kriging based on daily coordinates (SP-TS). The method SP-TS is also by far much more time consuming; the Kriging procedure has to be repeated for the whole network for each single day. On the other hand the method SP-TS could be regarded as more robust in the way that, if a few days of interpolation fail it would easily be detected and removed in the final time-series analysis. Method SP-TS is also able to predict non-linear features for instance expected yearly fluctuations for a site.

The modeled velocities (GIA-3D) are compared with real observations in the same way as we did for the statistical interpolated velocities. The RMS values are included in Table 1 . In the horizontal components GIA-3D and SP-VF perform equally, but in the vertical component the statistical interpolated values fit better to the observations. Horizontal motions are dominated by plate tectonic processes, which make isolating the GIA signal difficult. With GIA-1D we have constrained our GIA model only using the vertical velocities. The GIA-1D model has better fit to vertical observations than the 
SP-VF. If we exclude the stations on the perimeter of the network (green triangles in Fig. 1), however, the SP-VF are closer to observations. To summarize, interpolation based on geophysical models gives better estimates on the edge of the network, but inside the network the statistical interpolation method is preferable.

To evaluate the interpolation in the vertical component using leveling (LP), we use the same 10 control stations (black circles in Fig. 1). The LP results perform at a level between the two results using Kriging (SP-VF and SP-TS). However, the LP results are hampered by the discrepancy in Trondheim (TRDS) (misfit of $1.3 \mathrm{~mm} /$ year). Removing Trondheim from the solution yields a RMS of $0.55 \mathrm{~mm} / \mathrm{year}$, similar to the GIA-1D. If we remove the three perimeter stations in addition the RMS is $0.45 \mathrm{~mm} / \mathrm{year}$. This is better than achieved with GIA-1D, but not at the level of SP-VF. In the Trondheim area the leveling shows a clear increase in the land uplift from west to east, a trend not so clear if we compare the GNSS time series in Trondheim with the neighbouring stations.

The GIA model indicates that the largest gradient in the uplift values is in mid-Norway. Unfortunately, this is also the area where we lack velocity estimates from the GNSS observations (the records here are currently too short to obtain reliable velocities). Figure 6 shows broad agreement between the leveling and GIA solutions in mid-Norway. Whereas, the Kriging solution shows large differences between both the leveling and GIA solutions in this area. For areas where we not yet have reliable velocity estimates from the GNSS observations, therefore, measurements from leveling can provide a useful additional constraint on velocity field solutions based on statistical methods.

\section{Discussion}

In Sect. 3 the agreement between part of the time-series and the complete time-series was evaluated for 10 different stations (black circles in Fig. 1). After 3.5 years of data the RMS was $0.3,0.3$ and $0.5 \mathrm{~mm} /$ year for the north, east and vertical components, respectively. These RMS values are at the same level as we achieved with SP-VF and GIA-3D in the horizontal components and slightly better in the vertical component. If we remove the outliers at the edge of the network (green triangles in Fig. 1), the precision of SP-VF in the vertical component is similar to what we achieved with 4.5 years time-series length compared to the complete time-series. To summarize, depending on the geometry of the network, statistical predictions and geophysical models give better precision than time-series with less than approximately 3.5 years of observations. For stations with longer time-series the observed velocities are preferable.
We have made two underlying assumption of the interpolation; (1) the deformations in Norway have a spatial wavelength longer than the distance between stations and (2) GIA and rigid plate tectonics are the dominant source of crustal movement in Norway.

Other geophysical processes that might introduce secular crustal deformation in Norway are neotectonics and loading from glaciers and large water reservoirs. All large water reservoirs in Norway were established before the Norwegian GPS network and will not introduce significant secular elastic deformations for the GNSS sites.

We do not expect that present-day glacier changes in Norway will have a large affect on the GNSS velocities as their mass changes are relatively small and such elastic deformations are confined to areas close to the mass changes (e.g. Khan et al. 2007; Kierulf et al. 2009b).

Although Norway is situated on the stable Eurasian plate and far from the plate margin, the seismological and neotectonical activities are relatively large. Geological evidence, seismological measurements as well as InSAR and GPS data indicate that the Ranafjord area (66.2 $2^{\circ}$ north) is the most tectonically active area in Norway (see Olesen et al. 2012). A GPS campaign network in the area has been occupied twice with 9 years separation. Results indicate a relative deformation of the network of $1 \mathrm{~mm} /$ year horizontally (Olesen et al. 2012). This is above the precision level found in this paper. Local deformation exceeding the $0.5 \mathrm{~mm} / \mathrm{year}$ can not be excluded in other neotectonically active areas of Norway.

Comparing the Kriging and GIA-model solutions reveals an interesting pattern of differences in the horizontal components (Fig. 6 upper right panel). This likely reflects errors in the GIA model solution and/or the presence of non-GIA related signals. Indeed, examining deviations from the GIA model solution may help identify non-GIA effects, this is something that could be explored in future investigations.

\section{Conclusion}

In this paper we have analyzed data from the permanent GNSS network in Norway using the GNSS analysis package GAMIT. The results are presented as time-series and velocity estimates are calculated. The precision and accuracy of these velocity estimates are examined with respect to time-series length.

All tests show a decline of the results if you have less than three years of data, especially in the vertical component. Results improve gradually when you extend your time-series length.

In the second part of this paper we have looked at several methods to predict velocities in areas where we do not have permanent GNSS receivers or the observation period is too short (less than three years) to calculate good 
Table 2 Uplift for some Norwegian stations

\begin{tabular}{llll}
\hline & $\begin{array}{l}\text { K2012 } \\
\text { ITRF2008 } \\
\text { mm/year }\end{array}$ & $\begin{array}{l}\text { L2010 } \\
\text { ITRF2005 } \\
\text { mm/year }\end{array}$ & $\begin{array}{l}\text { L2007 } \\
\text { ITRF2000 } \\
\text { mm/year }\end{array}$ \\
\hline OSLS & $5.11 \pm 0.33$ & $6.51 \pm 0.47(-0.15 \pm 0.28)$ & $5.78 \pm 0.42(0.99 \pm 0.53)$ \\
STAS & $1.46 \pm 0.17$ & $2.90 \pm 0.42(-0.15 \pm 0.28)$ & $1.18 \pm 0.51(0.98 \pm 0.53)$ \\
TRDS & $4.31 \pm 0.35$ & $6.19 \pm 0.51(-0.13 \pm 0.28)$ & $3.80 \pm 0.58(1.05 \pm 0.53)$ \\
TRO1 & $2.90 \pm 0.33$ & $4.61 \pm 0.83(-0.10 \pm 0.28)$ & $2.30 \pm 0.49(1.13 \pm 0.53)$ \\
VARS & $2.67 \pm 0.28$ & $5.74 \pm 0.86(-0.07 \pm 0.28)$ & $1.89 \pm 1.13(1.14 \pm 0.53)$ \\
\hline
\end{tabular}

K2012 is from this study, L2010 is from Lidberg et al. (2010) and L2007 is from Lidberg et al. (2007). Numbers in parenthesis is the vertical component of the transformation parameters between the reference frames and should be added to the uplift value to transform them to ITRF2008

velocity estimates. Two different statistical interpolation methods based on Kriging theory are performed as well as an interpolation method using a geophysical GIA-model and a method using repeated leveling. The models are comparable, but the velocities based on geophysical models are more robust on the perimeter or outside the GNSS network, while the statistical method give better results inside the network. Our results indicate that velocity estimates based on the different interpolation methods are better than that estimated from a single GNSS station which has less than 3.5 years of data.

Acknowledgments We would like to acknowledge the SATREF group at the Norwegian Mapping Authority for there effort to establish the permanent GNSS network in Norway necessary for this study and especially Oddgeir Kristiansen for his work to collect and maintain an archive of Norwegian GNSS stations. We would like to thank IGS for providing necessary geodetic infrastructure and geodetic products. The authors also thank the reviewers for constructive feedback that helped to improved the original manuscript considerably.

Open Access This article is distributed under the terms of the Creative Commons Attribution License which permits any use, distribution, and reproduction in any medium, provided the original author(s) and the source are credited.

\section{Appendix}

\subsection{Earlier results and reference frame}

In Table 2 we present vertical velocities for stations which are included in this study and also included in previous studies (Lidberg et al. 2007, 2010). We find differences between the different studies. Taking the uncertainties and transformation into account the differences between this study and Lidberg et al. (2007) are relatively small, but the uplift in Lidberg et al. (2010) seems a bit too large.

Differences between the different ITRFs have been discussed extensively in several papers (e.g., Argus 2007; Teferle et al. 2009; Lidberg et al. 2010; Altamimi et al.
2011). In Norway the differences between ITRF2000 and ITRF2008, based on the transformation parameters (Altamimi et al. 2007, 2011), are approximately 1, 0 and $1 \mathrm{~mm} /$ year, in the north-, east- and height-component, respectively. The formal uncertainties in the transformation parameters between different reference frames do not necessarily reflect the uncertainty of the reference frame relative to geophysical processes. Wu et al. (2011) find that ITRF2008 is consistent with the earth mean center of mass at the 0.2 mm/year level. In Collilieux and Wöppelmann (2011) the ITRFs are extensively discussed in the context of global sealevel.

Differences between results of geodetic studies represent an issue for the correct understanding of geophysical processes (see e.g. King et al. 2010). To obtain better constraint on the GNSS results we can use independent observations such as other geometric techniques like Very Long Baseline Interferometry (VLBI) and Satellite Laser Ranging (SLR) (e.g., Altamimi et al. 2011) non-geometric techniques like gravimetry (e.g., Teferle et al. 2009; Omang and Kierulf 2011) or geophysical evidence (e.g., Argus 2007; Kierulf et al. 2009b). Individual components of the Global Geodetic Observing System (GGOS) (e.g. Rummel et al. 2005) have to be maintained and improved.

\section{References}

Altamimi Z, Collilieux X, Legrand J, Garayt B, Boucher C (2007) ITRF2005: a new release of the international terrestrial reference frame based on time series of station positions and earth orientation parameters. J Geophys Res 112:b09401 OSE doi:10.1029/ 2007JB004949

Altamimi Z, Collilieux X, Métivier L (2011) ITRF2008: an improved solution of the international terrestrial reference frame. J Geodesy 85:457-473. doi:10.1007/s00190-011-0444-4

Argus FA (2007) Defining the translation velocity of the reference frame of earth. Geophys J Int 169(3):830-838. doi:10.1111/j.1365-246X. 2007.03344.x

Blewitt G, Lavallée D (2002) Effect of annual signals on geodetic velocities. J Geophys Res 107(2145):11. doi:10.1029/2001JB000570

Boehm J, Werl B, Schuh H (2006) Troposphere mapping functions for GPS and very long baseline interferometry from European 
Centre for medium-range weather forecasts operational analysis data. J Geophys Res 111:B02-406 doi:10.1029/2005JB003629

Bos M, Bastos L, Fernandes R (2010) The influence of seasonal signals on the estimation of the tectonic motion in short continuous GPS time-series. J Geodynamics 49:205-209. doi:10.1016/j.jog.2009.10. 005

Boucher C, Altamimi Z (2011) Memo: specifications for reference frame fixing in the analysis of a EUREF GPS campaign, v8. http:// etrs89.ensg.ign.fr/

Collilieux X, Wöppelmann G (2011) Global sea-level rise and its relation to the terrestrial reference frame. J Geodesy 85:9-22. doi:10. 1007/s00190-010-0412-4

Cressie NAC (1993) Statistics For Spatial Data. Wiley Series in Probability and Mathematical Statistics, isbn: 978-0-471-00255-0.

Fjeldskaar W (1994) Viscosity and thickness of the asthenosphere detected from the Fennoscandian uplift. Earth Planet Sci Lett 126:399-410

Herring T, King R, McClusky S (2011) Introduction to GAMIT/GLOBK release 10.4. Tech. rep. Massachusetts Institute of Technology, Cambridge.

Hill EM, Davis JL, Tamisiea ME, Lidberg M (2010) Combination of geodetic observations and models for glacial isostatic adjustment fields in Fennoscandia. J Geophys Res 115:B07403. doi:10.1029/ 2009JB006967

Johansson J, Davis J, Scherneck HG, Milne G, Vermeer M, Mitrovica J, Bennett R, Jonsson B, Elgered G,Elosegui P, Koivula H, Poutanen M, Ronnang B, Shapiro I (2002) Continous GPS measurements of postglacial adjustment in Fennoscandia 1. Geodetic result. J Geophys Res 107(B8):2157. doi:10.1029/2001JB000400

Johnson HO, Agnew DC (1995) Monument motion and measurements of crustal velocities. Geophys Res Lett 22(21):2905-2908. doi:10. 1029/95G102661

Kendall RA, Mitrovica JX, Milne GA (2005) On postglacial sea level: II. numerical formulation and comparative results on spherically symmetric models. Geophys J Int 161(3):679-706. doi:10.1111/j.1365246X.2005.02553.x

Khan SA, Wahr J, Stearns LA, Hamilton GS, van Dam T, Larson KM, Francis O (2007) Elastic uplift in southeast Greenland due to rapid ice mass loss. Geophys Res Lett 34:L21701. doi:10. 1029/2007GL031468

Kierulf HP, Plag HP, Kristiansen O (2003) Towards the true rotation of a rigid Eurasia. In: Torres JA, Hornik $\mathrm{H}$ (eds) EUREF Publication No. 12, Verlag des Bundesamtes für Kartographie und Geodäsie, Frankfurt am, Main, pp 118-124.

Kierulf HP, Pettersen B, McMillan D, Willis P (2009) The kinematics of Ny-Ålesund from space geodetic data. J Geodynamics 48:37-46. doi:10.1016/j.jog.2009.05.002

Kierulf HP, Plag HP, Kohler J (2009) Measuring Surface deformation induced by present-day ice melting in Svalbard. Geophys J Int 179(1):1-13. doi:10.1111/j.1365-246X.2009.04322.X

King M, Altamimi Z, Boehm J, Bos M, Dach R, Elosegui P, Fund F, Hernndez-Pajares M, Lavallèe D, Mendes Cerveira P, Penna N, Riva R, Steigenberger P, van Dam T, Vittuari L, Williams S, Willis P. (2010)Improved constraints on models of glacial isostatic adjustment: a review of the contribution of ground-based geodetic observations. Surv Geophys 31:465-507. doi:10.1007/s10712-0109100-4

Lambeck K, Smither C, Ekman M (1998a) Tests of glacial rebound models for Fennoscandinavia based on instrumented sea- and lakeleve records. Geophys J Int 135:375-387

Lambeck K, Smither C, Johnston P (1998b) Sea-level change, glacial rebound and mantle viscosity for northern Europe. Geophys J Int 134:102-144

Legrand $\mathrm{J}$, Bergeot $\mathrm{N}$, Bruyninx $\mathrm{C}$, Wöppelmann $\mathrm{G}$, Bouin MN, Altamimi Z (2010) Impact of regional reference frame definition on geodynamic interpretations. J Geodynamics 49 (3-4):116-122.doi:10.1016/j.jog.2009.10.002, WEGENER 2008 Proceedings of the 14th General Assembly of Wegener

Lidberg M, Johansson J, Scherneck HG, Davis J (2007) An improved and extended GPS derived velocity field for the glacial isostatic adjustment in Fennoscandia. J Geodesy 81(3):213-230. doi:10. 1007/s00190-006-0102-4

Lidberg M Johansson JM, Scherneck HG, Milne GA (2010) Recent results based on continuous GPS observations of the GIA process in Fennoscandia from BIFROST. J Geodynamics 50:1

Mao A, Harrison CGA, Dixon TH (1999) Noise in GPS coordinate time series. J Geophys Res 104(B2):2797-2816. doi:10.1029/ 1998JB900033

Milne G, Davis J, Mitrovica J, Scherneck HG, Johansson J, Vermeer M, Koivula H (2001) Constraints on glacial isostatic adjustments in Fennoscandia. Science 291:2381-2385

Milne GA, Mitrovica JX, Scherneck HG, Davis JL, Johansson JM (2004) Continuous GPS measurements of postglacial adjustment in Fennoscandia: 2. modeling results. J Geophys Res 109:B02412. doi:10.1029/2003JB002619

Mitrovica JX, Milne GA (2003) On postglacial sea level: I. general theory. Geophys J Int 154(2):253-267. doi:10.1046/j.1365-246X

Mitrovica JX, Davis JL (1994) A spectral formalism for computing three-dimensional deformations due to surface load, 2. present-day glacial isostatic adjustment. J Geophys Res 99:7075-7101

Nocquet JM, Calais E, Parsons B (2005) Geodetic constraints on glacial isostatic adjustment In Europe. Geophys Res Lett 32:L06308. doi:10. 1029/2004G1022174.1022174

Olesen O, Brönner M, Dehls J, Lindholm C, Bungum H, Kierulf H, Bockmann L (2012) Neotectonics and strandflat formation in Nordland, northern Norway. Geophys Res Abstr 14:EGU2012-13080

Omang OCD, Kierulf HP (2011) Past and present-day ice mass variation on Svalbard revealed by superconducting gravimeter and GPS measurements. Geophys Res Lett 38:L22304. doi:10.1029/ 2011GL049266

Rummel R, Rothacher M, Beutler G (2005) Integrated global geodetic observing system (IGGOS) - science rationale. J Geodynamics 40 $(4-5): 357-362$

Santamaria-Gomez A, Bouin MN, Collilieux X, Wöppelmann G (2011) Correlated errors in GPS position time series: implications for velocity estimates. J Geophys Res 116:B01405. doi:10.1029/ 2010JB007701

Scherneck HG (1991) A parametrized solid earth tide model and ocean tide loading effects for global geodetic baseline measurements. Geophys J Int 106(3):677-694. doi:10.1111/j.1365-246X.1991. tb06339.x

Scherneck HG, Johansson J, Elgered G, Davis J, Jonsson B, Hedling G, Koivula H, Ollikainen M, Poutanen M, Vermeer M, Mitrovica J, Milne GA (2002) BIFROST: Observing the threedimensional deformation of Fennoscandia. In: Mitrovica X, Vermeersen BLA (eds) Ice Sheets Sea Level and the Dynamic Earth. American Geophysical Union, Washington, pp 69-93

Sorensen D, Gianola G (2002) Likelihood, Bayesian, and MCMC methods in quantitative genetics. Springer, Berlin

Steffen H, Wu P (2011) Glacial isostatic adjustment in Fennoscandia: a review of data and modeling. J Geodyn 52(3-4):160-2004. doi:10. 1016/j.jog.2011.03.002

Teferle FN, Bingley RM, Orliac EJ, Williams SDP, Woodworth PL, McLaughlin D, Baker TF, Shennan I, Milne GA, Bradley SL, Hansen DN (2009) Crustal motions in Great Britain: evidence from continuous GPS, absolute gravity and Holocene sea level data. Geophys J Int 178:23-46. doi:10.1111/j.1365-246X.2009.04185.x

Teza G, Pesci A, Casula G (2012) Strain rate computation in northern Victoria land (Antarctica) from episodic GPS surveys. Geophys J Int 189:851-862. doi:10.1111/j.1365-246X.2012.05403.x

Vespe F, Rutigliano P, Ferraro C, Nardi A (2002) Vertical Reference Systems, IAG Symposia, vol 124. In: Drewis H, Dodson AH, 
Fortes LPS, Sanchez L, Sandoval P (eds) Vertical motions from geodetic and geological data: a critical discussion of the results. Springer, Berlin Heidelberg, pp 66-71

Vestøl O (2006) Determination of postglacial land uplift in Fennoscandia from leveling, tide-gauges and continuous GPS stations using least squares collocation. J Geodesy 80:248-258. doi:10. 1007/s00190-006-0063-7

Williams SDP (2008) CATS: GPS coordinate time series analysis software. GPS Solut 12(2):147-153. doi:110.1007/s10291-1000710086-10294

Williams SDP, Bock Y, Fang P, Jamason P, Nikolaidis RM, Prawirodirdjo L, Miller M, Johnson DJ (2004) Error analysis of continuous GPS position time series. J Geophys Res 109:1-19
Wu X, Collilieux X, Altamimi Z, Vermeersen B, Gross R, Fukumori I (2011) Accuracy of the international terrestrial reference frame origin and earth expansion. Geophys Res Lett 38:L13304. doi:10.1029/2011GL047450

Zhang J, Bock Y, Johnson H, Fang P, Williams S, Genrich J, Wdowinski S, Behr J (1997) Southern California permanent GPS geodetic array: error analysis of daily position estimates and site velocities. J Geophys Res 102(B8):18035-18055. doi:10.1029/ 97JB01380 